\title{
A pregnancy with GDM, hypothyroidism, polyhydramnios with history of treatment for subfertility
}

\author{
Soumya Mukherjee ${ }^{1}$, Sukanta Sen $^{2 *}$, Sukanta Misra ${ }^{3}$
}

\begin{abstract}
${ }^{1}$ Department of Obstetrics and Gynecology, Nehru Memorial Techno Global Hospital, Barrackpur Cantonment, West Bengal, India

${ }^{2}$ Department of Pharmacology, ICARE Institute of Medical Sciences and Research, Haldia, West Bengal, India

${ }^{3}$ Department of Obstetrics and Gynecology, Ramakrishna Mission Seva Pratishthan Vivekananda Institute of Medical Sciences, Kolkata, West Bengal, India
\end{abstract}

Received: 19 January 2018

Accepted: 28 February 2018

\section{*Correspondence:}

Dr. Sukanta Sen,

E-mail: drsukant@gmail.com

Copyright: ( $)$ the author(s), publisher and licensee Medip Academy. This is an open-access article distributed under the terms of the Creative Commons Attribution Non-Commercial License, which permits unrestricted non-commercial use, distribution, and reproduction in any medium, provided the original work is properly cited.

\begin{abstract}
Gestational diabetes (GDM) is defined as carbohydrate intolerance that begins or is first recognized during pregnancy. Although it is a well-known cause of pregnancy complications, its epidemiology has not been studied systematically. There are several identifiable predisposing factors for GDM, and in the absence of risk factors, the incidence of GDM is low. Low thyroid hormone levels in early pregnancy are a risk factor for GDM incidence. Although gestational hyperthyroidism is uncommon $(0.2 \%)$, hypothyroidism (autoimmune disease or suboptimal iodine intake) occurs in $2.5 \%$ of women and is predictive of reduced neonatal and child neuropsychological development and maternal obstetric complications. It is well documented that thyroid disorders are associated with maternal and fetal complications during gestation and sequelea after delivery. The case-finding strategy does not solve the serious problem of leaving undiagnosed and untreated patients without risk factors. In the absence of strong evidence that support universal thyroid screening in pregnancy, current guidelines suggest a case-finding approach targeting thyroid function testing in high-risk groups. A couple have history of sub-fertility. Patient conceived following treatment. During pregnancy, GDM developed and later half of pregnancy was complicated by polyhydramnios. Baby was delivered by LSCS due to PPROM.
\end{abstract}

Keywords: Disorders, Gestational diabetes, Hypothyroidism, Pregnancy

\section{INTRODUCTION}

The thyroid undergoes physiological changes during pregnancy, such moderate enlargement of the gland and increasing of vascularization. Beta-Human chorionic gonadotropin $(\beta-\mathrm{HCG})$ causes thyroid stimulation since the first trimester, due to structural analogy with thyroidstimulating hormone (TSH). ${ }^{1}$

The thyrotropic activity of $\beta$-hCG causes also a decrease in serum TSH in the first trimester so that pregnant women have lower serum TSH concentrations than nonpregnant women. ${ }^{2}$

The circulating levels of thyroid-binding globulin (TBG) are also increased by estrogen stimulation. On the other hand the increased renal clearance both fetal intake and placenta metabolism induce a relative decline in the availability of iodide. ${ }^{3}$

Study has shown that GDM occurred in $12.3 \%$ of women in the study cohort. Of the women with hypothyroidism, 
$14.3 \%$ developed GDM compared to $5.8 \%$ of hyperthyroid women. Caesarean delivery was significantly higher in women with hypothyroidism versus women with hyperthyroidism $(\mathrm{p}=0.002) .^{4}$

Few prospective studies have shown that thyroid dysfunction in early pregnancy may have adverse effects on pregnancy outcome and offspring. The incidence of GDM increased with increasing prepregnancy body mass index $(\mathrm{P}<0.0001)$.

Pregnant women with a family history of diabetes had a much higher incidence of GDM than those without a family history of diabetes $(21.09 \%$ vs $12.92 \%$; $\mathrm{P}<0.0001$ ). The level of free T4 (FT4) in early pregnancy in GDM women was lower than that in non GDM women $(\mathrm{P}<0.0001)$. With increasing early pregnancy $\mathrm{FT} 4$, the rate of incident GDM was decreasing $(\mathrm{P}<0.0001){ }^{5}$

Although gestational hyperthyroidism is uncommon $(0.2 \%)$, hypothyroidism (autoimmune disease or suboptimal iodine intake) occurs in $2.5 \%$ of women and is predictive of reduced neonatal and child neuropsychological development and maternal obstetric complications.

Therefore, screening for thyroid dysfunction in pregnancy should be considered. T4 and thyroid stimulating hormone measurements could be used to screen for hypothyroidism, which would require levothyroxine intervention treatment. ${ }^{6}$

Endocrinal disorders are one of the important causes of Infertility. Similarly, pregnancy complicated by endocrine disorders carries risk both for mother and baby. Besides Biochemical investigation, ultrasonography plays an important role in these situations.

\section{CASE REPORT}

A 26years of aged primigravida woman reported her LNMP 21/10/2014, EDD 28/07/2015. Her past menstrual cycle was regular. She is a known patient of hypothyroidism; on Tablet Eltroxin $(100 \mathrm{mcg})$. She married for 5years. Couple has tried for an issue for last 4 years. Patient was initially treated with ovulation induction agent namely clomiphene citrate. Patient was undergone Lap \&Dye test on 18/09/2014. Per operative findings was flimsy adhesion at pouch of douglas and around bilateral adnexa. Adhesiolysis was done. Bilateral tubal spillage of dye was noticed. Following operation patient received a course of doxycycine. Patient was advised to continue Tablet Eltroxin (100mcg) along with folic acid supplementation. Family History: Mother is a known patient of Diabetic Mellitus.

Patient attended her first antenatal check up on $07 / 12 / 2014$. On examination, body weight $55 \mathrm{~kg}$, BP $110 / 80 \mathrm{mmHg}$, uterus was not palpable. She was advised to continue tab Eltroxin (100), folic acid Tablet and to do the antenatal investigation.

On her subsequent visit, investigation revealed $\mathrm{Hb} \%$ 10gm $\%$, ABO/Rh Typing O +ve, TSH $3.8 \mu \mathrm{Iu} / \mathrm{ml}$, FBS $168 \mathrm{mg} / \mathrm{ml}$, serology non reactive. Dose of Tablet Eltroxin reduced to $75 \mathrm{mcg}$. She was advised to follow strict diabetic diet and to do Oral Glucose Tolerance Test (OGTT) with 100gram Glucose. OGTT report showed fasting $110 \mathrm{mg} / \mathrm{ml}$, $1 \mathrm{st} \mathrm{hr} 150 \mathrm{mg} / \mathrm{ml}$, $2 \mathrm{nd} \mathrm{hr} 170 \mathrm{mg} / \mathrm{ml}$, $3 \mathrm{rd} \mathrm{hr} 123 \mathrm{mg} / \mathrm{ml}$. As per advice of an Endocrinologist, moderate exercise (walking) \& strict diabetic diet were recommended for her.

First trimester USG (23/12/2014) showed single live foetus of 9 weeks 4days gestational age. Patient received two doses of inj Tetanus toxoid at interval of 4 weeks. She was advised to continue haematinics and calcium supplementation. USG FPP with anomalies scan was done on $20 / 03 / 2015$. It revealed single live foetus of 21 weeks 6 days. No gross congenital anomaly detected. Amniotic fluid volume revealed excess with amniotic fluid index $18.2 \mathrm{~cm}$.

On her subsequent visit, it was noticed that uterine fundal height was more than her period of amenorrhoea, to locate the foetal heart rate (FHR), foetal doppler was needed. Around 34 weeks of gestational age, patient was complaining of shortness of breath, pain abdomen. Patient was treated conservatively. USG FPP revealed single live foetus, with polyhydramnios [Figure 1].

Around 36 weeks, patient was complaining of acute respiratory distress (it was due to polyhydramnios) with pain abdomen. On examination, FHR $144 \mathrm{bpm}$, fundal height was large for her gestational age, tense abdomen, patient was not in labour. Patient \& her husband explained and counselled. Patient admitted (on 30/06/2015), received inj Betamethasone $12 \mathrm{mg}$ intramuscular (two doses, at 24hour apart). Blood investigation showed well controlled glycemic status. On 1st July, early morning patient complaining of watery discharge per vagina.

On examination, frank dribbling was noticed. The case was diagnosed as preterm pre-labour ruptured of membranes. 2nd dosing betamethasone (12mg) was given. Emergency LSCS was done under spinal anaesthesia. Per operative finding was liquor volume excess and clear. Baby was delivered by vertex, cried after birth. At birth weight was $3.25 \mathrm{~kg}$. Baby was monitor for hypoglycaemic attack for 24 hour post-operative period was uneventful.

\section{DISCUSSION}

Infertility is serious challenge to the modern day gynaecologist. Different male and female factors may influence the infertility. Endocrine disorder interferes with conception. Uncontrolled hypothyroidism is 
associated with anovulation, poor endometrial receptivity, obesity which in turn reduces the probability of conception. ${ }^{7}$ Overall incidence of pregnancy with hypothyroidism is about $2.5 \%$.

Untreated hypothyroidism in early pregnancy has increased risk of abortion, prematurity, and subnormal mental development of the neonate. Replacement therapy is with thyroxine, 50 to $100 \mu \mathrm{g}$ daily. Serum thyrotropin levels are measured at 4 to 6 weeks' intervals and thyroxin adjusted by $25-50 \mu \mathrm{g}$ increments until they reach normal values. ${ }^{8}$

The term Gestational Diabetes Mellitus (GDM) includes cases with abnormal carbohydrate tolerance with onset or first detected during the present pregnancy. In Indian prospective, universal screening for detection of GDM is recommended. ${ }^{9,10}$ The method employed is by using 50 gm oral glucose tolerance without regards to time of day or last meal, between 24-28 weeks of pregnancy. Cut off value was considered $140 \mathrm{mg} \%$ at 1 hour.

GDM has some adverse effects on mother and foetus, though the incidence are much lower compare to pregnancy with overt diabetes. Foetus has risk of congenital anomalies (4-10\%) namely VSD, ASD, neural tube defects, sacral agenesis, and duodenal atresia etc. There is $30-40 \%$ risk of foetal macrosomia. The foetus has increased risk of unexplained intrauterine foetal death. Pregnancy is associated with abortion, preterm labour, pre-eclampsia, polyhydramnios, prolong labour, shoulder dystocia etc. Nearly $50 \%$ of women with GDM would develop overt diabetes over a follow up period of 5 to 20 years. ${ }^{11,12}$

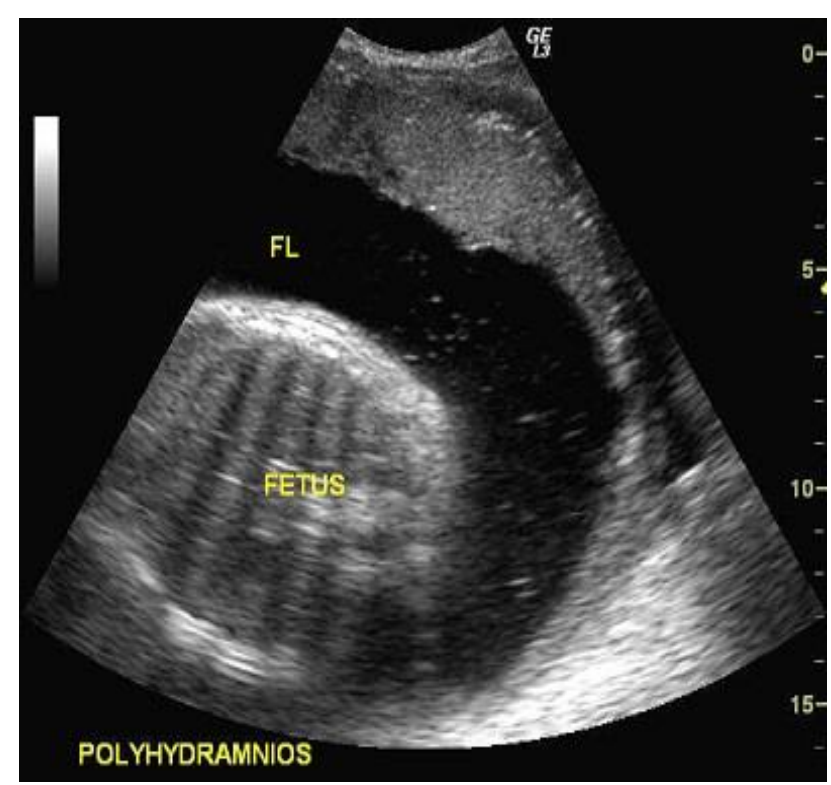

Figure 1: Sonography of a pregnancy with polyhydramnios: images show excess amniotic fluid (the largest single pocket measuring $11.5 \mathrm{cms}$. approximately).
Study had shown that hypothyroidism was observed in 8 $(16 \%)$ and hydronephrosis of maternal kidneys in $3(6 \%)$ of diabetic pregnancies, while none of these were noted in the nondiabetic pregnancies. The incidence of pregnancy-induced hypertension (PIH); hypothyroidism and polyhydramnios were also observed more in diabetic pregnancies. ${ }^{13}$ Good glycemic control is mandatory and it can be done by diet, exercise with or without insulin. Ultrasonography of pregnancy profile, anomaly scan as well as foetal echocardiography plays a very important role in this type of high risk pregnancy.

Thyroid function is influenzed by pregnancy and its dysfunction is associated with maternal and fetal morbidity. If larger studies confirm the trends observed in our case report, consideration should be given to including women with known thyroid disease in the subset of women who should be offered screening for diabetes early in pregnancy and appropriate clinical surveillance.

\section{ACKNOWLEDGMENTS}

Authors would like to thank Dr. Nirupam, Dr. Khanna for his support during study.

\section{Funding: No funding sources}

Conflict of interest: None declared

Ethical approval: The study was approved by the Institutional Ethics Committee

\section{REFERENCES}

1. Soldin OP, Tractenberg RE, Hollowell JG, Jonklaas J, Janicic N, Soldin SJ. Trimester-specific changes in maternal thyroid hormone, thyrotropin, and thyroglobulin concentrations during gestation: trends and associations across trimesters in iodine sufficiency. Thyroid. 2004;14(12):1084-90.

2. Negro R. Significance and management of low TSH in pregnancy. The Thyroid and Reproduction. Georg Thieme Verlag, New York. 2009 Jun 17:84-95.

3. Casey B, Leveno K. Thyroid disease in pregnancy. Obstet Gynecol. 2006;108(5):1283-92.

4. Stohl HE, Ouzounian J, Rick AM, Hueppchen NA, Bienstock JL. Thyroid disease and gestational diabetes mellitus (GDM): is there a connection? J Matern Fetal Neonatal Med. 2013;26(11):1139-42.

5. Yang S, Shi FT, Leung PC, Huang HF, Fan J. Low Thyroid Hormone in Early Pregnancy Is Associated with an Increased Risk of Gestational Diabetes Mellitus. J Clin Endocrinol Metab. 2016;101(11):4237-43.

6. Lazarus JH, Premawardhana LD. Screening for thyroid disease in pregnancy. J Clin Pathol. 2005;58(5):449-52.

7. Dashe J, Casey B, McIntire D, Wells CE, Byrd W, Leveno $\mathrm{K}$ et al. Use of a pregnancy specific nomogram for TSH to improve screening for thyroid disease Am J Obstet Gynecol. 2003;189(6):S188. 
8. Singer PA, Cooper DS, Levy EG, Ladenson PW, Braverman LE, Daniels G, et al. Treatment guidelines for patients with hyperthyroidism and hypothyroidism. JAMA. 1995;273(10):808-12.

9. Sheffield JS, Butler-Koster EL, Casey BM, McIntire DD, Leveno KJ. Maternal diabetes mellitus and infant malformation. Obstet Gynecol. 2002;100(5):925-30.

10. Pedersen J. The pregnant Diabetic and her Newborn, $2^{\text {nd }}$ ed. Baltimore, Williams and Wilkins, 1977,211.

11. O'Sullivan JB. Body weight and subsequent diabetes mellitus. JAMA.1982;248:949.

12. Jovanovic-Peterson L. Medical Management of Pregnancy Complicated by Diabetes. Alexandria, VA, American Diabetes Association; 1995.
13. Saxena P, Tyagi S, Prakash A, Nigam A, Trivedi SS. Pregnancy outcome of women with gestational diabetes in a tertiary level hospital of North India. Indian J Prev Soc Med. 2011;36(2):120-3.

Cite this article as: Mukherjee S, Sen S, Misra S. A pregnancy with GDM, hypothyroidism, polyhydrramnios with history of treatment for subfertility. Int J Reprod Contracept Obstet Gynecol 2018;7:2034-7. 